\title{
Pituitary autoantibodies in patients with hypopituitarism and their relatives
}

\author{
S Strömberg, P Crock ${ }^{1}, \AA ̊$ Lernmark ${ }^{2}$ and A-L Hulting \\ Department of Endocrinology and Diabetology, Karolinska Hospital, Stockholm, Sweden, ${ }^{1}$ Department of Paediatrics, John Hunter Children's Hospital, \\ Newcastle, New South Wales, Australia and ${ }^{2}$ Department of Medicine, University of Washington, Seattle, Washington, USA \\ (Requests for offprints should be addressed to S Strömberg, Department of Endocrinology and Diabetology, Karolinska Hospital L1:02, \\ S-171 76 Stockholm, Sweden)
}

\begin{abstract}
Autoantibodies to human pituitary cytosol proteins were determined by immunoblotting in sera from patients with hypopituitarism and their relatives. Reactivity to an $M_{\mathrm{r}}$ 49000 protein was significantly more frequent in patients $(6 / 21(28 \%) P<0 \cdot 05)$ as well as in relatives $(10 / 35(28 \%)$ $P<0 \cdot 02)$ compared with controls $(3 / 44(6 \cdot 8 \%))$. Autoantibodies to this particular protein have previously been detected in sera from $70 \%$ of patients with biopsy-proven lymphocytic hypophysitis. Unlike patients with biopsyproven lymphocytic hypophysitis, none of the patients in
\end{abstract}

this study presented with a suspected pituitary adenoma or showed an enlarged sella turcica. Cisternal herniation was seen in 6/21 patients and this may very well represent the end stage of lymphocytic hypophysitis. Since organ specific autoantibodies are frequent in patients with autoimmune endocrine disease as well as in their unaffected relatives, autoantibodies to this $M_{\mathrm{r}} 49000$ pituitary cytosolic protein may represent markers for an immunological process affecting the pituitary gland.

Journal of Endocrinology (1998) 157, 475-480

\section{Introduction}

Hypopituitarism is most commonly explained by pituitary adenomas or by causes such as cranial irradiation, head trauma, infarction due to pituitary apoplexy or sarcoidosis. However, in some patients other causes of pituitary dysfunction must be considered. As in other endocrine organs, it is reported that the pituitary may also be the target for an autoimmune process (Goudie \& Pinkerton 1962, Hume \& Roberts 1967, Asa et al. 1981). This condition is usually referred to as lymphocytic hypophysitis, and is characterised by chronic inflammation and destruction of the anterior pituitary. Approximately 100 patients have been reported since the first description of the disorder in 1962 (Goudie \& Pinkerton 1962). The classical presentation is peripartum hypopituitarism, often with pituitary mass and visual failure (Feigenbaum et al. 1991, Thodou et al. 1995). The diagnosis has been based on histological samples of pituitary biopsies or postmortem tissue. Because of the risks associated with the neurosurgical procedure, biopsies are only indicated in patients whose pituitary pathology is unclear by computed tomography (CT) or magnetic resonance imaging (MRI). The radiological images of lymphocytic hypophysitis vary depending on time duration of the pathological process (Cosman et al. 1989). However, both CT and MRI may indicate a completely normal sella turcica (Mau et al. 1994). Therefore, a number of patients with hypo- pituitarism of unknown origin may have undiagnosed autoimmune pituitary disease. It is most important to diagnose this condition since autoimmune pituitary disorder may be fatal if secondary adrenocorticotrophic hormone (ACTH) and thyroid-stimulating hormone (TSH) insufficiency are not identified (Richtsmeier et al. 1980, Gal et al. 1986).

Autoimmunity of endocrine organs is characterised by the development of autoantibodies to specific autoantigens in the target organ. The presence of pituitary autoantibodies in sera from patients with hypopituitarism is therefore thought to be a marker for autoimmune pituitary disease. Pituitary autoantibodies have been detected in sera from patients with hypopituitarism or other endocrine diseases (Bottazzo et al. 1975, Mirakian et al. 1982, Sugiura et al. 1986, Kobayashi et al. 1988, Komatsu et al. 1988). Methodological problems have, however, hampered the characterisation of pituitary autoantigens. Recently, immunoblotting with human pituitary proteins (Crock et al. 1993) allowed detection and characterisation of pituitary autoantibodies in sera from patients with biopsy-proven lymphocytic hypophysitis (Crock 1998).

In this study we describe a group of patients with verified hypopituitarism. All other major causes of their hypopituitarism had been excluded and pituitary autoimmunity was therefore suspected. The presence of pituitary autoantibodies in these patients and their relatives 
was investigated using the above described immunoblotting method. The clinical features of our patients with hypopituitarism were compared with the clinical data recorded in the literature on patients with lymphocytic hypophysitis.

\section{Subjects and Methods}

Subjects

Patients with hypopituitarism A total of 11 men and 10 women treated for hypopituitarism of unknown origin at the Department of Endocrinology and Diabetology, Karolinska Hospital participated in this study (Table 1). The age range was $24-87$ years. Their medical histories were evaluated and blood samples collected for analysis of pituitary autoantibodies.

Family members Blood samples were collected from 35 family members (first degree relatives and husband or wife) for pituitary autoantibody analysis. There were 15 men and 20 women, the age range being $22-80$ years.

Positive control Serum from a patient with biopsyproven lymphocytic hypophysitis and pituitary autoantibodies by immunoblotting was used as a positive control.

Normal controls Sera from 44 healthy subjects from the Stockholm area were used as controls in the pituitary autoantibody analysis. There were 28 men and 16 women, age range 21-60 years. Exclusion criteria were major illness or autoimmune disease.

The study was approved by the Ethics Committee of the Karolinska Hospital. All subjects gave informed consent.

\section{Methods}

Detection of pituitary autoantibodies by immunoblotting Normal human pituitary tissue was obtained at autopsy, $4-8 \mathrm{~h}$ post mortem and frozen at $-70{ }^{\circ} \mathrm{C}$. A total of ten pituitaries was homogenised in phosphate-buffered saline (PBS) with protease inhibitors. The homogenate was centrifuged to give a cytosolic fraction. The cytosolic fraction was depleted of immunoglobulin $\mathrm{G}$ ( $\operatorname{IgG}$ ) using protein A Sepharose (Pharmacia, Uppsala, Sweden) and stored in aliquots at $-70{ }^{\circ} \mathrm{C}$. Pituitary samples were boiled for two min in the presence of 1,4-dithiothreitol. The cytosol preparations were subjected to $10 \times 10.5 \mathrm{~cm}$ sodium dodecylsulphate (SDS)-polyacrylamide gels $(10 \%$ running gel, 4\% stacking gel) by electrophoresis. A total amount of $50 \mu \mathrm{g}$ protein was loaded in each well. Molecular weight markers (Bio-Rad, Hercules, CA, USA) were included in each experiment. After electro- phoresis, the proteins were transferred to polyvinylidene difluoride (PVDF; Bio-Rad) transfer membranes. After blocking for $1 \mathrm{~h}$ in $5 \%$ fat-free skimmed milk (BLOTTO)/PBS, membranes were divided into ten lanes using a Deca-Probe Incubation Manifold (Hoefer, San Francisco, CA, USA). Lanes were incubated with patient, relative or control serum diluted 1:50 in 1\% BLOTTO/ PBS on a shaker at $4{ }^{\circ} \mathrm{C}$ overnight. Control lanes were incubated with $1 \%$ BLOTTO/PBS only. Following incubation the membranes were washed with PBS-0.05\% Tween 20 and incubated with alkaline phosphataseconjugated goat anti-human IgG antiserum (SigmaAldrich; Sigma, St Louis, MO, USA) diluted 1:2500 in 1\% BLOTTO/PBS for $1 \mathrm{~h}$ at room temperature on a shaker. After final washing, membranes were incubated with 5-bromo-4 chloro-3 indolyl phosphate and nitroblue tetrazolium until colour development was optimal. Results of the immunoblotting assay experiments were reported independently by two observers who were blinded to the status of the serum samples. For further technical information see Crock et al. (1993).

\section{Statistical analyses}

Reactivity to cytosolic proteins by immunoblotting was compared between groups using Fisher's exact test.

\section{Results}

\section{Clinical findings}

Among the patients (Table 1), three women and three men had panhypopituitarism (patients 1-6). One of the women (patient 1) also had vasopressin deficiency for which she received treatment. The duration of symptoms for these six patients varied. Two of the men had already had symptoms in childhood (patients 5 and 6). None of the six patients had any other suspected autoimmune disease. One woman in our study only exhibited prolactin (PRL) secretion (patient 7). She received her diagnosis rather late in life, after a short duration of symptoms. One man exhibited only growth hormone $(\mathrm{GH})$ secretion (patient 8). Four patients had selective ACTH deficiency (patients 9-12). They were all women who were diagnosed after the age of 30 years. Their duration of symptoms varied from one week up to one year. Two of these patients had other suspected autoimmune diseases showing antibodies towards parietal cells and cardiolipin (patients 11 and 12). One male (patient 13) with multiple endocrinopathies, diabetes mellitus, thyroiditis, vitiligo and pernicious anaemia, was evaluated because of a clinical history and symptoms pointing to hypopituitarism. Lymphocytic hypophysitis was suspected, but at the time of laboratory evaluation, signs and symptoms had disappeared and only isolated prolactin deficiency could be proven. Three 

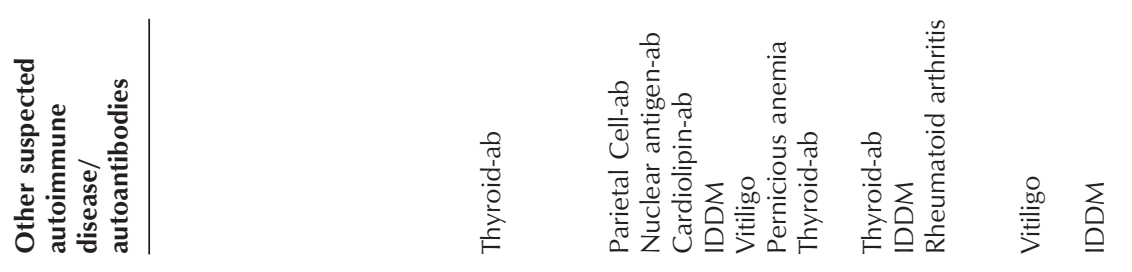

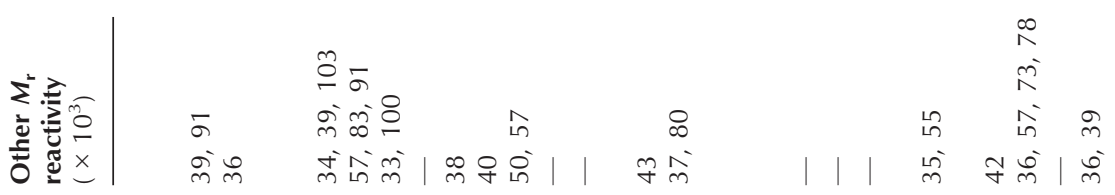
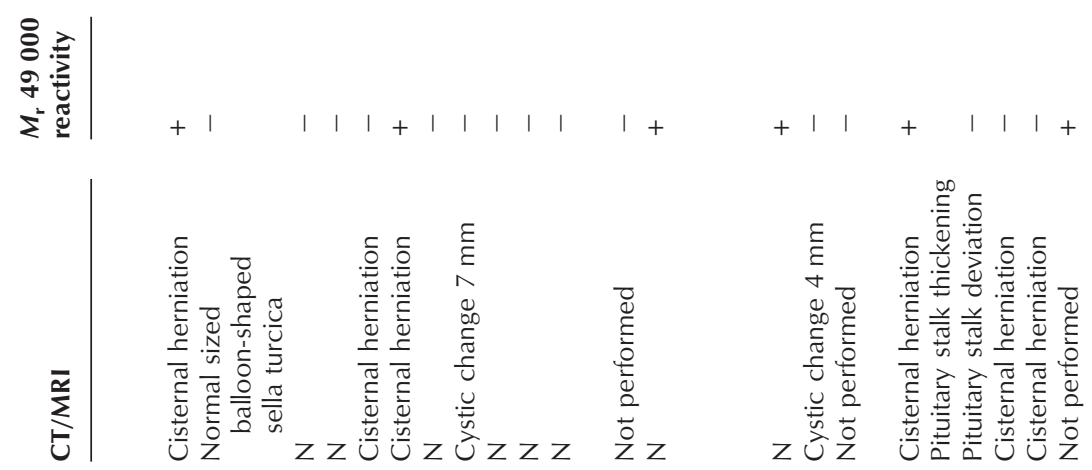

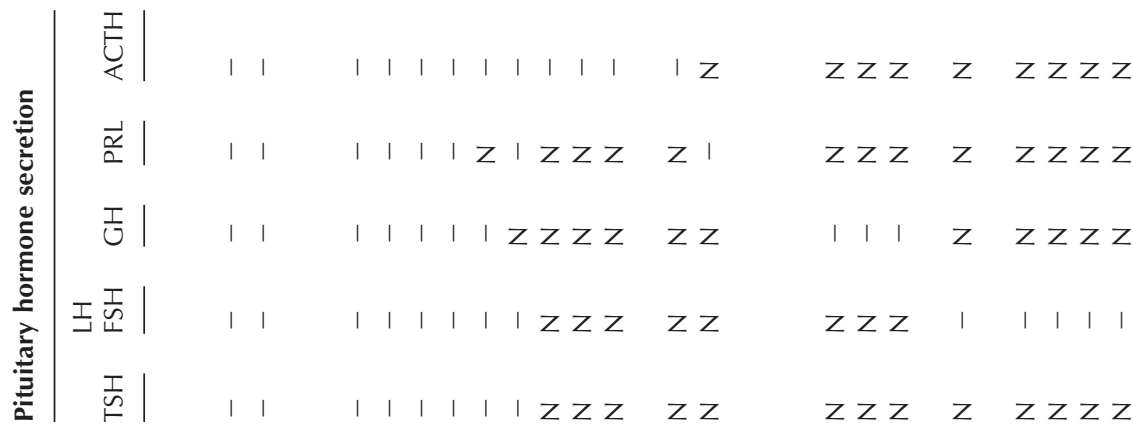

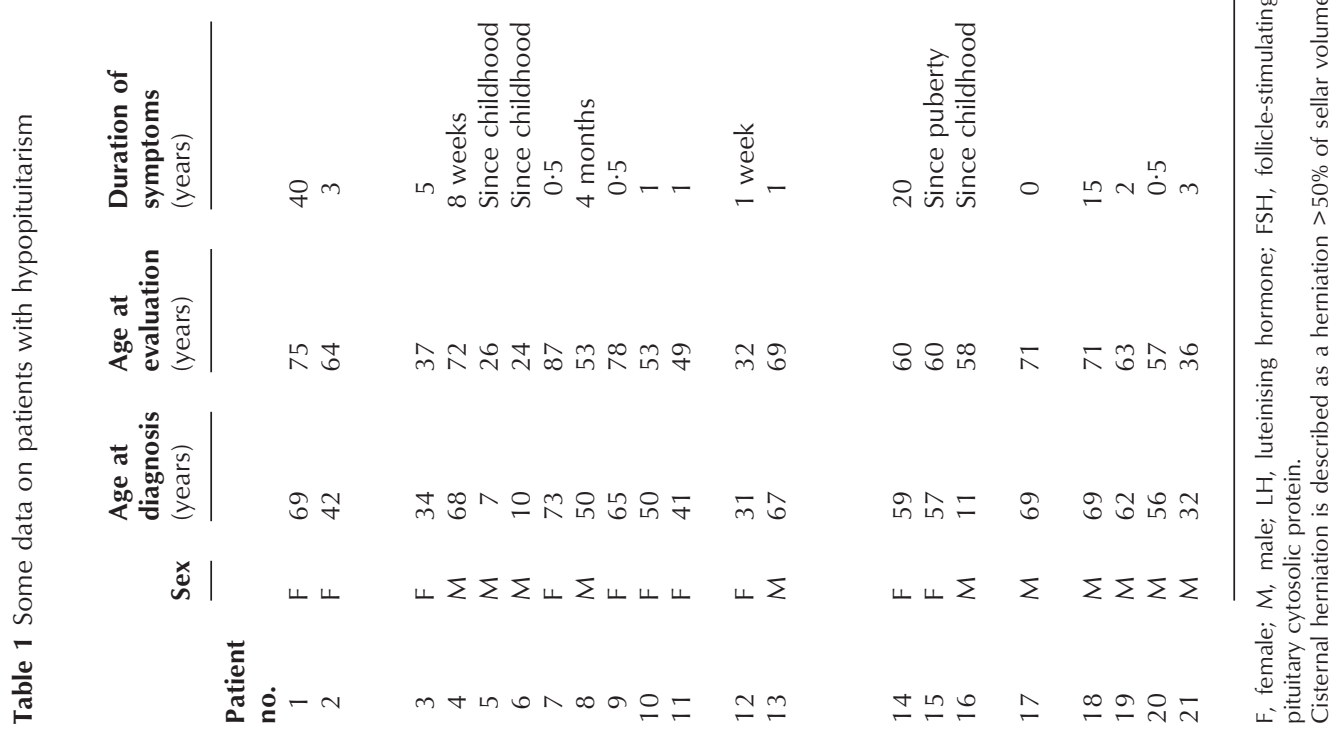


patients had isolated GH insufficiency (patients 14-16). Other autoimmune diseases were known in two of these patients. Finally, five patients suffered from isolated gonadotrophin deficiency (patients 17-21). Duration of symptoms varied between 0.5 and 15 years. Two of these patients had other known autoimmunity (patients 18 and 20).

Clinical evaluation showed that fatigue was the most common symptom (seen in $12 / 21$ patients). Decreased libido $(5 / 21)$ and impotence $(5 / 21)$ were also frequent, while eye symptoms were not noticed in any of the patients. One patient (no. 17) was asymptomatic at the time of diagnosis. His gonadotrophin deficiency was revealed at a routine health check-up.

\section{Radiological examinations}

Eight patients exhibited normal findings, while ten patients had pathological findings by CT or MRI (Table 1). Six patients showed cisternal herniation of varying degree with none or little visible pituitary tissue left. Two patients had pituitary cysts. One patient had a balloon-shaped sella turcica of normal size, one patient showed pathological pituitary stalk deviation and another a pathologically thick pituitary stalk with intense contrast loading. No patient had an enlarged sella turcica and suspected pituitary tumour could not be seen in any patient. CT and MRI were not performed in three cases.

\section{Pituitary autoantibodies}

Six of the 21 (28\%) patients with hypopituitarism showed reactivity to an $M_{\mathrm{r}} 49000$ pituitary cytosolic protein (Table 1). Sera from 10/35 (28\%) family members also reacted with this protein (Table 2). Of the control sera, 3/44 (6.8\%) showed $M_{\mathrm{r}} 49000$ reactivity. Statistical analysis proved that patients as well as relatives showed $M_{\mathrm{r}}$ 49000 reactivity in significantly higher frequencies than controls $(P<0.05$ and $P<0.02$ respectively). Figure 1 shows this $M_{\mathrm{r}} 49000$ reactivity in some sera. A number of other pituitary cytosolic proteins were detected by individual sera, but there were no significant patterns or differences between patients, relatives and controls (Table 1).

\section{Discussion}

This study shows that patients with hypopituitarism of unknown cause have a significantly higher prevalence of autoantibodies to an $M_{\mathrm{r}} 49000$ pituitary cytosolic protein compared with control subjects. The role of autoantibodies in the development of autoimmune disease is unclear but they are believed to be markers for these diseases. Autoantibodies to this $M_{\mathrm{r}} 49000$ pituitary protein have been detected in 7/10 (70\%) sera samples from patients
Table 2 Tabulation of relatives with $M_{r} 49000$ reactivity. Their relationships to patients with hypopituitarism as well as additional $M_{\mathrm{r}}$ reactivity are shown. Details of the patients are taken from Table 1. Patients 5, 7 and 9 exhibited other $M_{\mathrm{r}}$ reactivity, whereas patients 14 and 21 as well as the 10 relatives were $M_{\mathrm{r}} 49000$ positive

\begin{tabular}{|c|c|c|c|}
\hline & Relative & $\begin{array}{l}M_{\mathrm{r}} 49000 \\
\text { reactivity }\end{array}$ & $\begin{array}{l}\text { Other } M_{\mathbf{r}} \\
\text { reactivity } \\
\left(\times 10^{3}\right)\end{array}$ \\
\hline \multirow[t]{2}{*}{$\begin{array}{l}\text { Patient no. } \\
5\end{array}$} & & - & 33.100 \\
\hline & Mother & + & 38 \\
\hline \multirow[t]{2}{*}{7} & & - & 38 \\
\hline & Daughter & + & - \\
\hline \multirow[t]{5}{*}{9} & & - & 50,57 \\
\hline & Sister & + & - \\
\hline & Brother & + & 33,62 \\
\hline & Husband & + & - \\
\hline & Daughter & + & - \\
\hline \multirow[t]{3}{*}{14} & & + & - \\
\hline & Daughter & + & - \\
\hline & Daughter & + & - \\
\hline \multirow[t]{3}{*}{21} & & + & 36,39 \\
\hline & Mother & + & 64 \\
\hline & Brother & + & - \\
\hline
\end{tabular}

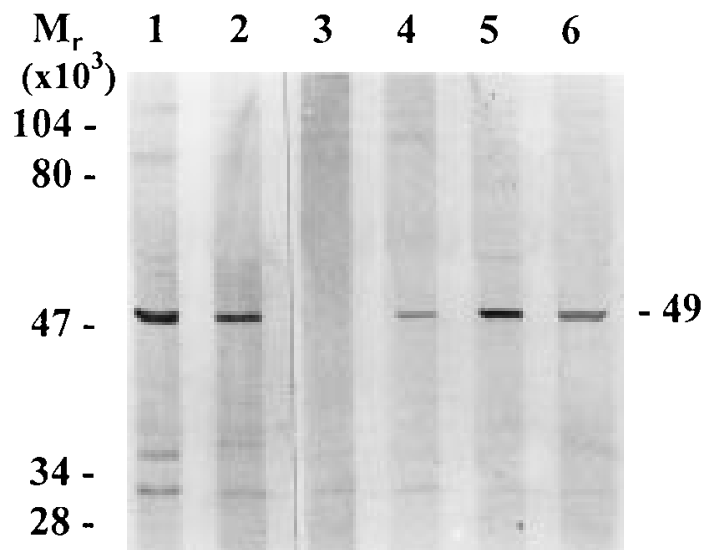

Figure 1 One immunoblotting experiment with human pituitary cytosol ( $50 \mu \mathrm{g}$ protein/well) as antigen, showing the reactivity in different sera. $M_{r}$, molecular mass markers $\left(\times 10^{3}\right)$. Lane 1, sera from the positive control patient with biopsy-proven lymphocytic hypophysitis, showing reactivity to an $M_{\mathrm{r}} 49000$ protein. Lanes 2 and 4, sera from patients 21 and 14 showing reactivity to an $M_{\mathrm{r}} 49000$ protein. Lane 3, sera from a normal control subject showing no reactivity to pituitary proteins. Lanes 5 and 6 , sera from two daughters of patient 14 , both showing reactivity to an M 49000 protein.

with biopsy-proven lymphocytic hypophysitis (Crock 1998). Therefore, we suggest that some of our patients with hypopituitarism of unknown cause may also have 
autoimmune pituitary disease which, for ethical reasons, cannot be confirmed by biopsy.

Relatives of patients with hypopituitarism of unknown cause also showed a significantly higher prevalence of autoantibodies to this $M_{\mathrm{r}} 49000$ pituitary cytosolic protein. None of these relatives showed any signs of pituitary insufficiency themselves; however, extensive pituitary function tests were not performed. Pituitary autoantibodies have not been analysed in relatives of patients with biopsy-proven lymphocytic hypophysitis. Autoantibodies to non-characterised rat pituitary cytosolic proteins have been described in a few family members of two patients with Sheehan's syndrome and one patient with partial hypopituitarism (Kajita et al. 1991). However, autoantibodies are often present among relatives of patients with organ-specific autoimmune diseases. In insulin-dependent diabetes mellitus (IDDM) for example, glutamic acid decarboxylase (GAD) autoantibodies are shown to be early and sensitive markers for later development of this autoimmune endocrine disease (Baekkeskov et al. 1987). In addition, relatives of GAD-positive patients are more likely to have GAD antibodies than control subjects, but they do not necessarily become diabetic. A combination of different autoantibodies and genetic markers seems to be crucial for development of IDDM (Hagopian et al. 1995). This might also be the case for pituitary autoimmune disease and may explain the absence of hypopituitarism in our autoantibody-positive relatives.

Previous reports of lymphocytic hypophysitis indicate a female predominance with a female:male ratio of $8 \cdot 5: 1$ (Thodou et al. 1995). We did not find a female predominance in the present study of 11 men and 10 women. Four out of six patients with autoantibodies to the $M_{\mathrm{r}} 49000$ pituitary cytosolic protein were men. This difference is difficult to interpret. One explanation may be the fact that our patients include men seeking medical attention for impotence and infertility problems due to gonadotrophin deficiency. This is of interest since these patients have not so far been thoroughly examined in respect to autoimmune pituitary disease.

A striking difference between our study of patients with hypopituitarism of unknown origin and biopsyproven cases of lymphocytic hypophysitis is the outcome of the radiological examination. Patients with biopsy-proven lymphocytic hypophysitis almost exclusively have enlarged pituitaries causing hypopituitarism and many of them have visual disturbances (Powrie et al. 1995). None of our patients had an enlarged pituitary on MRI/CT examinations and a pituitary tumour was not suspected in any case. Nor did any of our patients complain of visual disturbances. Thus, pituitary biopsy was not indicated. Three of our $M_{\mathrm{r}} 49000$ antibody-positive patients showed cisternal herniation, and this was also the predominant pathological finding in the patient group, i.e. $6 / 10$ patients with sellar pathology showed cisternal herniation. A combination of clinical symptoms, laboratory data, radio- logical results and pituitary pathology data reveals that lymphocytic hypophysitis probably progresses through different stages (Cosman et al. 1989). In the acute phase of the disease, the pituitary gland is enlarged, but later the pituitary tissue may be more or less destroyed by the severe inflammation. Shrinkage and atrophy of the pituitary gland is seen as a common end stage of this process. The cisternal herniation seen in a number of our patients may very well represent the end stage of lymphocytic hypophysitis.

Most patients with biopsy-proven lymphocytic hypophysitis were described as having acute symptoms of pituitary insufficiency because of their severe pituitary inflammation. On the other hand, we believe that a gradual inflammatory process affecting the pituitary gland may cause a slowly developing pituitary insufficiency as noticed in many of our patients. The patients in our study presented with selective hormone deficiency as well as total panhypopituitarism. This is also known for patients with biopsy-proven lymphocytic hypophysitis (Jensen et al. 1986, Cosman et al. 1989).

Subclinical forms of endocrine autoimmune disease during pregnancy, i.e. thyroiditis may develop into overt disease after delivery (Amino et al. 1977). This also seems to be the case for lymphocytic hypophysitis, that often causes partial or total hypopituitarism in women ante, during or post partum. Our patient group contained two women (patients 3 and 12) who developed hypopituitarism in relation to pregnancy. Neither of these two patients showed reactivity to the $M_{\mathrm{r}} 49000$ pituitary cytosolic protein.

Coexistent autoimmune disease is reported in approximately thirty percent of patients with biopsy-proven lymphocytic hypophysitis. Overall we found a similar prevalence in our study. Interestingly, it was those patients with selective pituitary hormone deficiencies who were more likely to have another autoimmune condition. None of the patients with panhypopituitarism had an underlying autoimmune disease. Only one of our $M_{\mathrm{r}} 49000$-positive patients suffered from other known autoimmune disease (patient 13). The three $M_{\mathrm{r}} 49000$ autoantibody-positive controls did not show any signs of pituitary dysfunction or other endocrinopathies.

In conclusion, we have identified autoantibodies to an $M_{\mathrm{r}} 49000$ pituitary cytosolic protein by immunoblotting in significantly higher frequencies in sera from patients with partial or total hypopituitarism and also in sera from their relatives. The results are in agreement with knowledge about specific autoantibodies in other autoimmune endocrinopathies like IDDM. The possibility of an hereditary immunological pituitary process causing partial or panhypopituitarism in some patients cannot be excluded.

\section{Acknowledgements}

We would like to thank Damien O'Dwyer for valuable help during the study. This study has been supported by 
grants from the Swedish Society of Medicine and the Novo Nordisk Foundation.

\section{References}

Amino N, Miyai K, Kuro R, Tanizawa O, Azukizawa M, Takai S, Tanaki F, Nishi K, Kawashima M \& Kumahara Y 1977 Transient postpartum hypothyroidism: fourteen cases with autoimmune thyroiditis. Annals of Internal Medicine 87 155-159.

Asa SL, Bilbao JM, Kovacs K, Josse RG \& Kreines K 1981 Lymphocytic hypophysitis of pregnancy resulting in hypopituitarism: a distinct clinicopathologic entity. Annals of Internal Medicine 95 166-171.

Baekkeskov S, Landin M, Kristensen JK, Srikanta S, Bruining GJ, Mandrup-Poulsen T, de Beaufort C, Soeldner JS, Eisenbarth G, Lindgren F, Sundkvist G, Dahlquist G, Palmer J \& Lernmark A 1987 Antibodies to a $64000 M_{\mathrm{r}}$ human islet cell antigen precede the clinical onset of insulin-dependent diabetes. Journal of Clinical Investigation 79 926-934.

Bottazzo GF, Pouplard A, Florin-Christensen A \& Doniach D 1975 Autoantibodies to prolactin-secreting cells of human pituitary. Lancet ii $97-101$.

Cosman F, Post KD, Holub DA \& Wardlaw SL 1989 Lymphocytic hypophysitis. Report of 3 new cases and review of the literature. Medicine 68 240-256.

Crock P 1998 Cytosolic autoantigens in lymphocytic hypophysitis. Journal of Clinical Endocrinology and Metabolism 83 609-618.

Crock P, Salvi M, Miller A, Wall J \& Guyda H 1993 Detection of anti-pituitary autoantibodies by immunoblotting. Journal of Immunological Methods 162 31-40.

Feigenbaum SL, Martin MC, Wilson CB \& Jaffe RB 1991 Lymphocytic adenohypophysitis: a pituitary mass lesion occurring in pregnancy. Proposal for medical treatment. American Journal of Obstetrics and Gynecology 164 1549-1555.

Gal R, Schwartz A, Gukovsky-Oren S, Peleg D, Goldman J \& Kessler E 1986 Lymphoid hypophysitis associated with sudden maternal death: report of a case review of the literature. Obstetrical and Gynecological Survey 41 619-621.

Goudie RB \& Pinkerton PH 1962 Anterior hypophysitis and Hashimoto's disease in a young woman. Journal of Pathological Bacteriology 83 584-585.

Hagopian WA, Sanjeevi CB, Kockum I, Landin-Olsson M, Karlsen AE, Sundkvist G, Dahlquist G, Palmer J \& Lernmark A 1995 Glutamate decarboxylase-, insulin-, and islet cell-antibodies and HLA typing to detect diabetes in a general population-based study of Swedish children. Journal of Clinical Investigation 95 1505-1511.
Hume R \& Roberts GH 1967 Hypophysitis and hypopituitarism: report of a case. British Medical Journal 2 548-550.

Jensen MD, Handwerger BS, Scheithauer BW, Carpenter PC, Mirakian R \& Banks PM 1986 Lymphocytic hypophysitis with isolated corticotropin deficiency. Annals of Internal Medicine $\mathbf{1 0 5}$ 200-203.

Kajita K, Yasuda K, Yamakita N, Murai T, Matsuda M, Morita H, Mori A, Murayama M, Tanahashi S, Sugiura M \& Miura K 1991 Anti-pituitary antibodies in patients with hypopituitarism and their families: longitudinal observation. Endocrinologia Japonica $\mathbf{3 8}$ 121-129.

Kobayashi I, Inukai T, Takahashi M, Ishii A, Ohshima K, Mori M, Shimomura Y, Kobayashi S, Hashimoto A \& Sugiura M 1988 Anterior pituitary cell antibodies detected in Hashimoto's thyroiditis and Graves' disease. Endocrinologia Japonica 35 705-708.

Komatsu M, Kondo T, Yamauchi K, Yokokawa N, Ichikawa K, Ishihara M, Aizawa T, Yamada T, Imai Y, Tanaka K, Taniguchi K, Watanabe T \& Takahashi Y 1988 Antipituitary antibodies in patients with the primary empty sella syndrome. Journal of Clinical Endocrinology and Metabolism 67 633-638.

Mau M, Ratner R \& Gindoff P 1994 Antipituitary antibodies in a postpartum woman with partial pituitary deficiency and a normal pituitary MRI scan. Southern Medical Journal 87 267-269.

Mirakian R, Cudworth AG, Bottazzo GF, Richardson CA \& Doniach D 1982 Autoimmunity to anterior pituitary cells and the pathogenesis of insulin-dependent diabetes mellitus. Lancet $\mathbf{i}$ 755-759.

Powrie JK, Powell M, Ayers AB, Lowy C \& Sönksen PH 1995 Lymphocytic adenohypophysitis: magnetic resonance imaging features of two new cases and a review of the literature. Clinical Endocrinology 42 315-322.

Richtsmeier AJ, Henry RA, Bloodworth JM Jr \& Ehrlich EN 1980 Lymphoid hypophysitis with selective adrenocorticotropic hormone deficiency. Archives of Internal Medicine 140 1243-1245.

Sugiura M, Hashimoto A, Shizawa M, Tsukada M, Maruyama S, Ishido T, Kasahara T \& Hirata Y 1986 Heterogeneity of anterior pituitary cell antibodies detected in insulin-dependent diabetes mellitus and adrenocorticotropic hormone deficiency. Diabetes Research 3 111-114.

Thodou E, Asa SL, Kontogeorgos G, Kovacs K, Horvath E \& Ezzat S 1995 Clinical case seminar: lymphocytic hypophysitis: clinicopathological findings. Journal of Clinical Endocrinology and Metabolism 80 2302-2311.

Received 18 December 1997

Accepted 16 January 1998 